\section{Sigvard Eklund: the uses and abuses of nuclear energy}

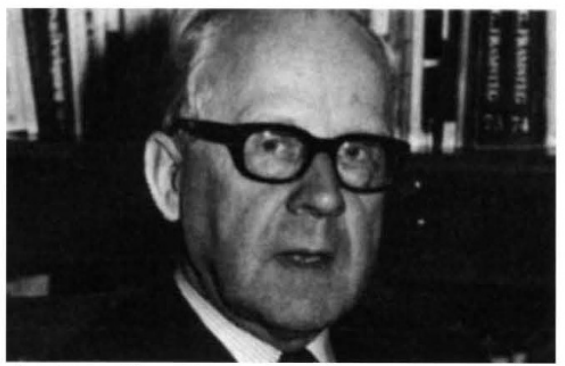

- The director-general of the IAEA (above) put the pro-nuclear case in London last week. Judy Redfearn reports

THE increased use of nuclear power has "not contributed to horizontal proliferation and is unlikely to", according to Dr Sigvard Eklund, director-general of the International Atomic Energy Agency (IAEA). At the presidential lecture of the British Institution of Nuclear Engineers in London last week, he supported this claim by saying that only six states have exploded nuclear weapons although many more have the technical know-how to do so.

The political will of states is the key to controlling proliferation, according to Eklund. Without it, international safeguards cannot be effective and "technical examinations are valueless".

Restricting the supply of enriched uranium and nuclear technology to developing countries, as advocated by the United States, is only likely to "encourage nuclear self-sufficiency and therefore increase proliferation", Eklund claims. $\mathrm{He}$ suggested the IAEA could work out a scheme to assure countries of essential nuclear supplies. This would have the strength of current non-proliferation arrangements and would assure supplies and safeguards. A disruption in supplies would be a breach of the safeguards. There was a need for urgent action, he said. "Nations would gain more in partnership than in imposing their thoughts on others."

Predictably Eklund is a staunch nuclear supporter. The nostalgia he feels for the time when nuclear engineers were left alone to solve difficult problems "quickly" and impossible ones "with time" illustrates his attitude towards the arguments of the antinuclear movement. "Rational arguments", he says, "no longer carry any weight."

Eklund believes that nuclear power will be needed to meet increasing world energy demand. $\mathrm{He}$ is sceptical of energy forecasting however: the great variety of estimates of future energy demand are not surprising, he says, considering the many different assumptions energy forecasters have made.

Nevertheless, he believes that the growth in demand will continue over the next decade (though the rate of growth will fall). Even if the developed countries use conservation measures, he says the world demand will continue because of increasing population, economic development, the development of sparsely populated areas (such as Siberia) and the energy needed to recycle increasingly scarce natural resources. "Even if the developed countries have zero energy growth, demand from developing countries will lead to a substantial growth in world energy needs."

Moreover, he says, conservation takes too long to have an effect to be a major factor in reducing energy demand before the end of the century. "Lifestyles and social structures don't change overnight, at least in democratic systems". Neither does he foresee any major role for alternative sources of energy. Those with the greatest potential such as hydroelectric power, he says, are already being exploited and others probably won't have much to offer.

So, in the expectation of increasing demand, Eklund sees nuclear power as ripe for a substantial contribution-at the right stage of development and economically competitive with other energy sources. "I don't believe uranium prices will rise faster than oil prices", he says, and substantial new discoveries of fossil fuels could only postpone the need for nuclear by a few decades. Oil is likely to become increasingly scarce and costly and a rapid expansion in coal production would lead to "serious environmental problems."

Eklund puts a lot of emphasis on fast breeder reactors which, he says, could double the energy potential of uranium and provide the world with abundant energy. Since 1973, however, there has been a drop in the number of FBR projects. "This constituttes a paradox", says Eklund. "Nuclear power has become the victim of the pioneering work on the environment done by its founders." The anti-nuclear movement has become allied to political groups which search for a better 'quality of life'-a term never defined, according to Eklund-rather than a higher 'standard of living'. These groups are not found in totalitarian states, he says: their greatest influence has been in countries with low majority governments such as Sweden and Austria.

\section{Can multinationals aid development?}

A RAPID technological transformation, similar to the industrial expansion of Japan in post-war decades, is now facing several developing countries scattered round the globe, according to $\mathrm{Dr}$ Jorge Katz, director of the Economic Commission for Latin America's research project on technology and development. Indeed, these nationswhich include Brazil, Argentina, Mexico, South Korea, Singapore, and perhaps even India-may soon be in a position to export advanced technical programmes to ather countriesalthough their spread will be on more limited industrial fronts than Japan's.

The slower-developing nations of Central and South America, and also Africa, then become the main targets for industrial and technological exports from their more advanced neighbours. The question then is what these less sophisticated nations will gain in the transaction.

It is generally assumed that developing countries which are used as the sites for the advanced industrial complexes of multinational corporations gain little in the way of technological knowledge of expertise. But Dr Katz challenged this view at a recent symposium at Sussex University, organised by the Science Policy Research Unit there. He maintained that developing nations were able to assimilate information from sophisticated manufacturing plants in their midst.

"You cannot take a piece of technology from a developed country, put it in a developing country and expect it to work in exactly the same way", he said. Altered circumstances often led to changes in plant design and in this way, local engineers and technologists became involved in work that increased their expertise.

However, a variety of economic factors affected the nature of technological transfer gained at plant level. One important determinant was the amount of freedom given by multinational companies to their foreign subsidiaries. For instance, many firms in the United States allowed their subsidiaries to vary original designs, while European, especially Swiss and German, companies tended to forbid this.

Other determinants included the rate of capital subsidy; the rate of exchange; and the cost and variability of local skilled labour. In some parts of Africa, there was practically no skilled labour available. This handicapped the setting up of new factories and in turn prevented new expertise being generated. Robin McKie 